\title{
A monarquia papal (1000-1300): a fundação de
}

\section{um conceito}

\author{
Leandro Duarte Rust ${ }^{[1]}$
}

\section{Resumo}

A vinculação do papado à história medieval sofreu profunda alteração após 1850. Até então habituais, as referências intelectuais sobre as características medievais do poder temporal dos papas tornaram-se genéricas e insuficientes. Um novo modelo interpretativo ganhou contornos, sobrepujando as explicações existentes. Ancorado na aplicação do método de crítica documental e reivindicando credenciais científicas, esse modelo fixou os séculos seguintes ao ano 1000 como período da institucionalização da Igreja romana, isto é, de sua transformação em uma monarquia papal. Com esse trabalho, buscamos esclarecer como se deu essa fundação historiográfica, analisando a importância do trabalho do erudito francês Paul Fabre e a publicação da edição moderna do Liber Censuum. Toda argumentação é orientada por uma hipótese: esse deslocamento epistemológico naturalizou certas categorias políticas oitocentistas na escrita da história medieval.

Palavras-chave: história medieval; monarquia papal; historiografia.

\section{La monarquía papal (1000-1300): la fundación de un concepto}

\section{Resumen}

El lugar ocupado por el papado en la historia medieval sufrió cambios profundos después de la décadade 1850. Las referencias intelectuales existentes sobre las características medievales del poder temporal del Papa fueron consideradas genéricas e insuficientes. Un nuevo modelo interpretativo tomó forma superando la aplicación del método crítico documental y reclamando credenciales científicas, este modelo se ha fijado los siglos posteriores al año 1000 como el periodo de la institucionalización de la Iglesia Romana, es decir, de su transformación en una monarquía papal. Con este trabajo, tratamos de aclarar cómo fue este fundamento historiográfico, mediante el análisis de la importancia de la labor del estudioso francés Paul Fabre y la publicación de la edición moderna del Liber Censuum. Todo el argumento está guiado por una hipótesis: este cambio epistemológico naturalizó ciertas categorías políticas del siglo XIX en la escritura de la historia medieval.

Palabras clave: historia medieval; monarquía papal; historiografía.

\section{The papal monarchy (1000-1300): the foundation of a concept}

\section{Abstract}

The place occupied by the papacy in medieval history under went profound change after the 1850s. The existing intellectual references on the medieval characteristics of the papal temporal power were considered generic and insufficient. A new interpretive model took shape surpassing the application of documentary critical method and claiming scientific credentials, this model has set the later centuries to the year 1000 as the period of the Roman Church institutionalization, ie its transformation into a papal monarchy. With this work, we seek to clarify how this historiographical foundation occurs, analyzing the importance of the work of the French scholar Paul Fabre and the publication of the modern edition of Liber Censuum. The central argument is guided by a hypothesis: this epistemological shift naturalized certain nineteenth-century political categories in the writing of medieval history.

Keywords: medieval history; papal monarchy; historiography.

\section{La monarchie papale (1000-1300): la fondation d'un concept}

\section{Resumé}

La place occupée par la papauté en l'histoire médiévale a subide profonds changements après la décennie de 1850. Les références intellectuelles existantes sur les caractéristiques médiévales du pouvoir temporel du pape ont été considérés comme génériques et insuffisantes. Un nouveau modèle d'interprétation a pris forme sur passant lapplication de la méthode critique et documentaire prétendant références scientifiques, ce modèle a mis dessiècles qui suivirent l'année 1000 comme la période de l'institutionnalisation de l'Église romaine, de sa transformation en une monarchie papale. Avec ce travail, nous cherchons à clarifier comment a eu lieu cette fondation historiographique, à travers l'analyse de l'importance des travaux du savant français Paul Fabre et la publication de l'édition moderne de Liber Censuum. Toute l'argumentation est guidé par une hypothèse: ce changement épistémologique a naturalisé certaines catégories politiques du XIXe siècle dans lécriture de l'histoire médiévale.

Mots-clés: histoire médiévale; monarchie papale; historiographie. 


\begin{abstract}
"Os problemas da teoria do conhecimento, tanto da clássica quanto da moderna, podem ser reduzidos ao problema da demarcação, isto é, ao problema de se encontrar o critério que determine o caráter empírico da ciência".
\end{abstract}

Karl Popper, 1968.

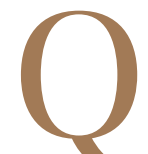

uando perderam de vista os Estados Papais, os historiadores os reencontraram no passado. Embora a governança papal desmoronasse há décadas, muitos estudiosos foram surpreendidos pela notícia alardeada aos quatro ventos pelos italianos em 1870: o sumo pontífice rendeu o último quinhão de terra sobre o qual reinava. Era Roma. Em setembro daquele ano, a cidade foi conquistada pelo reino da Itália e transformada em capital da nova nação que unificou toda a península (Fiorentino, 1990, p. 285-333)². E então, o papa se viu convertido em um príncipe sem reino, um governante sem estado. Destituído do poder temporal, Pio IX (1792-1878) recusou as ofertas de indenização e declarou: a captura da cidade equivalia a um encarceramento. Era o mesmo que amordaçá-lo, sequestrando sua santa prerrogativa de conduzir a sociedade para uma vida verdadeiramente cristã.

Por sessenta anos, os sucessores sustentaram essa postura de um autodeclarado "prisioneiro do Vaticano" (Kertzer, 2004). Leão XIII (1837-1903), Pio X (1835-1914) e Bento XV (1854-1922) não consentiam que altares e estabelecimentos católicos fizessem parte da pátria italiana, tampouco admitiram a participação católica na vida política da nação recém-unificada ${ }^{3}$. Enquanto a questão acirrava os ânimos no coração da península, um erudito da Escola Francesa de Roma indagou a história medieval de modo inovador. A pergunta, propriamente falando, não surpreendia, pois comichava em muitas mentes: quando surgiu aquela estrutura de poder que se esfarelava em plena luz do dia? Era a resposta que abrigava a novidade: resultados científicos indicavam que o atual governo dos Estados Papais se impôs no Ocidente entre 1000 e 1300. Nesse período, estavam guardadas as chaves da compreensão plena sobre as razões que moviam os pontífices na vida política europeia. Os Estados Papais combatidos pelos nacionalistas italianos eram uma criação medieval - demonstrou Paul Fabre. A resposta circulava por livros e universidades muito antes dele. Mas não daquele modo. Antes dele, a afirmação era uma opinião política corrente ou até mesmo um postulado religioso. Depois dele, ela seria exibida como verdade científica.

\title{
Coordenadas historiográficas: o papado medieval como objeto da ciência
}

Não era a primeira vez que alguém formulava tal ideia. Ao contrário, as raízes medievais do governo temporal dos papas foi tema recorrente em todo o Oitocentos. $\mathrm{O}$

\footnotetext{
2Ver, igualmente: Beales; Biagini (2005).

'Esse antagonismo entre a Santa Sé e o Estado Italiano ficaria conhecido como "a questão romana", sendo solucionado apenas em 1929, quando a assinatura do Tratado de Latrão, entre Pio XI e Mussolini, assegurou o reconhecimento do papa como chefe de estado. Ver: Kertzer (2014).
} 
próprio presente se encarregava de renovar o interesse sobre as origens históricas de um fenômeno político mais e mais controverso. Ocupados por Napoleão (1769-1821) no início do século, restaurados pelo Congresso de Viena em 1815, combatidos pelos rebeldes de Giuseppe Garibaldi (1807-1882) e pelos soldados do rei Vítor Emanuel II (1820-1878), os territórios governados pelos papas atraíram uma crescente atenção de pensadores, juristas, políticos e religiosos.

Em 1829, enquanto trilhava a brilhante carreira clerical que colocaria sua vida na trajetória de um disparo fulminante em uma barricada em Paris, Denis Auguste Affre alertava: compreender o poder temporal reclamado no Vaticano exigiria "remover o pó de Idade Média que paira sobre opiniões" (Affre, 1829, p. 3). O tom se manteve por décadas. Enquanto a atmosfera de guerra contra a Igreja romana despertava engajamentos apaixonados, a era medieval seguia sendo evocada como chave explicativa, ou melhor, como a matriz das ações e alegações pontifícias. Gelásio I (410-496), Gregório VII (1020?-1085) e Inocêncio III (1161?-1216) eram frequentemente apontados como os mestres políticos cujas lições continuavam sendo praticadas no Vaticano um milênio depois. Assim concordavam autores com pensamentos muito diferentes, como o abade Céleste Alix (Alix, 1860), o bispo Louis-Antoine de Salinis (Salinis, 1860), o advogado e jornalista Charles Malves-Pons (Malves-Pons, 1860),o congressista whig Joseph Chandler (M'Clintock, 1855) ${ }^{4}$ e o geógrafo e cientista Antonio SniderPellegrini (Snider-Pellegrini, 1860). Mas o interesse pela Idade Média estava a serviço da desenvoltura moralizante das obras. O mérito histórico era empurrado para segundo plano. Terminava eclipsado pela verve do engajamento polêmico. Afinal, a ordem do pensamento era ditada pela opinião inicial: todos os argumentos eram enfileirados a partir deum posicionamento prévio do autor, se ele julgava aceitável ou não que papas governassem a sociedade civil. Como fizera Joseph Marie de Maistre no famosíssimo Du Pape, a história era recrutada para defender julgamentos já formados;as alusões ao passado eram armas empunhadas em uma guerra de identidades (Maistre, 1841).E não apenas entre católicos e protestantes, mas entre quem se assumia como "religioso" ou como "nacionalista", "tradicionalista" ou "moderno".

O próprio papado converteu a questão em ponto de ebulição das tensões sociais. Ele o fez à medida que fomentou esta certeza: a redução de seu poder temporal era o sintoma de um colapso da religião, arruinada pelos avanços da modernidade. Sitiado por investidas militares e ideológicas do Reino da Itália, o clero vaticano radicalizava a resistência ano a ano. No entanto, anúncios como o da encíclica Quanta Cura (1864) e da elevação da infalibilidade papal a dogma de fé (1870) não despertavam somente cumplicidade ou resignação. A insistência do papa em estigmatizar o materialismo, o naturalismo e a livre consciência convencia muitos contemporâneos de que a Cúria se tornara uma trincheira antimoderna, onde o progresso e a laicidade eram combatidos como

"Trata-se de uma compilação de discursos realizados por Chandler na House of Representatives of Pennsy/vania: Ver: Gerrity (1982, p. 106-120). 
depravações infernais. ${ }^{5}$ Chamados à arena ideológica, partidários e adversários da autoridade católica lançaram-se ao debate sobre o significado histórico do governo papal. Então, a Idade Média veio à tona. Porém, mesmo quando surgia amparado em documentos confiáveis, esse interesse pelo medievo era pontual, secundário. Era um recurso ilustrativo empregado por erudições muitas vezes diletantes, como a marca de autoridade ocasionalmente emprestada a um argumento pré-fixado.

\section{O interesse pela Idade Média estava a serviço da desenvoltura moralizante das obras. O mérito histórico era empurrado para segundo plano}

Com os holofotes políticos apontados para a questão, seria um engano imaginar que o tema não atrairia atenções mais detidas à história. Nesse contexto, despontaram obras onde a leitura histórica era o componente dominante. Algumas delas se tornaram modelos reproduzidos e emulados pelas gerações seguintes. Tal foi o caso de Pouvoir du pape au Moyen Âge, ou Recherches historiques sur la souveraineté temporelle du Saint-Siége et sur le droit public du Moyen Âge, lançado em 1839 pelo abade Jean E. Auguste Gosselin (Gosselin, 1845). Bastaram 15 anos para o livro ganhar uma segunda edição - revista e ampliada - e cruzar o Atlântico para receber tradução em Baltimore. Outro caso semelhante foi The Growth of the Temporal Power of the Papacy: a historical review, lançado por Alfred Owen Legge em 1870 (Legge, 1870).Confessadamente motivado pela repercussão do Concílio Vaticano I, o livro contou com acolhida favorável nos meios acadêmicos (Vaughan, 1870, p. 554).Contudo, a primeira obra que dispensou a categoria genérica de "poder temporal" e reivindicou uma atenção específica para a origem dos Estados Papais foi redigida pelo reverendo irlandês John Miley. ${ }^{6}$

Quando publicou os três volumes de The history of the Papal States: from their Origin to the present Day (Miley, 1850), Miley operou uma conversão do olhar. Sua abordagem ensinava ser preciso apontaravisão para uma direção diferente daquela tracejada pela narrativa hegemônica. Divulgada por autores como Jean E. A. Gosselin e Leopold von Ranke (Ranke, 1878),essa narrativa apresentava a genealogia de vidas pontifícias como o centro causal de toda a política papal. Observada dessa maneira, a trajetória do governo papal

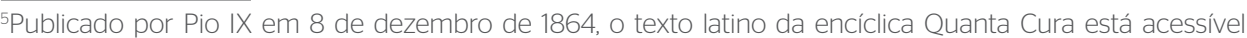
em: Denzinger; Schönmetzer, 1997, p. 483. A definição dogmática da infalibilidade papal foi redigida na IV seção do Concílio Vaticano I, ocorrida em 18 de julho de 1870, econsta em: Acta et decreta sacrosancti et oecumenici Concilii Vaticani die 8. decembris 1869 a ss. d. n. Pio p. IX inchoati, 1871, p. 180-184. Para o contexto de publicação da encíclica e do dogma da infalibilidade papal, nos baseamos em: Schelkens; Dick; Mettepenningen, (2013, p. 7-89); Costigan (2005); Oakley (2003, p. 250-264).

${ }^{6}$ É preciso retificar uma informação divulgada alhures. Em artigo anterior, atribui a autoria de The history of the Papal States: from their Origin to the present Day a um reverendo metodista norte-americano, homônimo do intelectual irlandês. Ver: Rust (2012, p. 130-138). Com base nas publicações Dublin Review e Spectator, essa caracterização da autoria deve ser corrigida. Ver: Dublin Review (1850, p. 123-141); The Spectator, (1850, p. 1000).
} 
no tempo assumia os traços de uma sucessão de empreendimentos pessoais. Rupturas e permanências eram explicadas como desventuras individuais ou sagas biográficas. A longa sequência de líderes eclesiásticos era encarada como eixo da história, postura que ganhou prestígio maior após 1851, ano em que o historiador e filólogo Philipp Jaffé publicou a monumental Regesta Pontificum Romanorum, ${ }^{7}$ ordenando mais de dez mil documentos a partir da cronologia de governo dos papas. A lição estava lavrada com autoridade acadêmica: a história marchava linearmente, conforme a morte revezava os nomes à frente da Igreja romana.

O reverendo irlandês, porém, propôs que o mesmo assunto fosse vislumbrado por outro ângulo. Era possível pensar o governo como um fenômeno em si, dotado de uma complexidade irredutível, não como mera extensão das decisões tomadas por um governante. A mudança de postura permitia contemplar uma nova paisagem de fatores históricos: era preciso levar em conta a geologia, a topografia e a hidrografia, pois elas definiam a territorialidade que condicionava o governo papal. Vias de comunicação e sítios populacionais eram igualmente relevantes, uma vez que determinavam os limites e vantagens dos recursos naturais e humanos. Como um naturalista oitocentista, Miley buscava compor um amplo quadro descritivo, abarcando do meio físico ao comércio, dos acervos linguísticos aos atos de poder (Miley, 1850).Com isso, na década de 1850, o reverendo ofereceu um ensinamento inovador: o estudo do governo pontifício na Idade Média extravasava as molduras de uma "História dos Papas".

O pioneirismo do intelectual irlandês só foi ofuscado por uma deficiência: The history of the Papal States carecia da aplicação de um método de crítica e de análise documental. Cultuado nas universidades germânicas e francesas como espinha dorsal do saber histórico, o rigor de uma análise metódica das "fontes históricas" parecia não ter influenciado John Miley. Com isso, em várias passagens, sua argumentação parecia flutuar entre as tipologias documentais; ora recorrendo a uma epístola, ora ancorando-se em uma crônica, sem explicitar os critérios norteadores de suas escolhas. $\mathrm{O}$ estudo dos Estados Papais, notadamente de sua formação e ascensão na Idade Média, seguiria assim por décadas: como um assunto de contornos muitas vezes opacos, imprecisos, que se confundia com a miscelânea de questões e temas reunidos em antigas coleções como a Rerum Italicarum Scriptores e a Antiquitates Italicae Medii Aevi, de Ludovico Antonio Muratori. ${ }^{8}$

Ao menos foi assim até que despontassem os trabalhos de Paul Fabre. Afinal, além dos próprios estudos, ele ofereceu aos leitores da época uma contribuição única, que determinaria as maneiras de conceber o papado medieval: a organização,a edição e publicação da coleção de registros manuscritos conhecida como Liber Censuum. Esse trabalho fez mais do que divulgar textos entesourados em arquivos, aquartelados sob a proteção ancestral de códices lacrados. A perícia documental de Paul Fabre acarretou efeitos maiores. Ela

${ }^{7} \mathrm{~A}$ obra de Jaffé foi expandida e atualizada nas décadas seguintes até atingir a versão consolida da segunda edição como: Jaffé; Lowenfeld; Kaltenbrunner; Ewald (1885-1888).

${ }^{8}$ As duas coleções datam de 1723-1743: Muratori (1965); Muratori (1914). 
naturalizou certas categorias conceituais típicas do ideário político moderno como registros objetivos da realidade. Grande parte dos critérios "técnicos e impessoais" aplicados sobre os manuscritos medievais que modelaram a nova edição documental consistia em ideias políticas de uma época - o século XIX. Exibidas como procedimentos metódicos, as atividades de seleção, transcrição, edição e comentário dos manuscritos raramente foram reconhecidas como uma prática social, isto é, como filtros informacionais historicamente construídos.

E assim, os resultados de uma classificação de informações guiada por valores políticos datados assumiram a feição de vestígios palpáveis de passado, de resquícios de uma realidade externa e pretérita ao estudioso, que "simplesmente" emergia outra vez em forma de texto. A partir de 1889, com o aparecimento da moderna edição do Liber Censuum,certos parâmetros da cultura política europeia do século XIX foram incorporados pelos historiadores como dados neutros e imutáveis. Vejamos como isto se deu.

\section{Editando formas, recortando conteúdos: a produção do olhar soberano}

Liber Censuum é o nome conferido a uma compilação de registros relativos a rendase patrimônios diretamente vinculados ao episcopado romano. Em 1192, Cêncio Savelli (1150-1227), cardeal diácono de Santa Lúcia in Sicilia e camerarius pontificio, entregou ao papa Celestino III (1106?-1198) 18 volumes de "escritos autênticos ou ordinários" a respeito das igrejas e monastérios, hospitais e casas mantidas pela caridade, cidades e castelos, propriedades ou casas especiais que se encontram sob o direito e a propriedade do bem-aventurado Pedro e da Santa Igreja Romana através do pagamento de censos. ${ }^{9}$

Para chegar à versão final, Cêncio percorreu uma miríade de fontes textuais. Estimar o fluxo censitário anual da Sé romana implicava reunir registros esparramados por séculos, embaralhados em uma multidão de escritos. Antes de Savelli, outros haviam tentado resumir os títulos e prerrogativas temporais atrelados à autoridade apostólica. Alguns anos antes, o cardeal Albino (?-1199) compôs uma Gesta pauperis scholaris, título dado a uma coleção sobre direitos da Igreja romana, referentes, sobretudo, a bens conferidos para os usos de clérigos pobres (Blumenthal, 1982, p. 7-49). Albino, por sua vez, havia se servido de outras compilações, muitas das quais em estado fragmentado e lacunar, caso do Liber Censuum Genuinus $^{10}$ (códex de tradição carolíngia, cuja versão então disponível era datada de fins do século XI); do Liber Politicus ${ }^{11}$ (redigido por um cônego regular de nome

\footnotetext{
9Descrição baseada no trecho: "[...] autentice scripta, seu ordinata, in scriptis de censibus redegissent, et posteri, sive sucessorum eorum, per memoralia ipsa, que ecclesie vel monasteria, hospitalia seu domus helemosinarie, que etiam civitates, castella, ville vel domus speciales, seu qui reges aut principes, in jus et proprietatem beati Petri et sancte Romane ecclesie persistentes censuales esse [...]." In: Fabre (1889 p. 3-24.).

${ }^{10}$ Acessível através de: Cenni (1761, p. 36); Migne (1841-1855, tomo 98, col. 475).

"Jean Mabillon intitulara o Livro como "Benedicti Beati Petri canonici liber pollicitus" e, ao editá-lo, converteu-o na introdução do Ordo Romanus. Ver: Mabillon (1689, p. 118)
} 
Bento e cuja datação era incerta $)^{12}$; de dois livroscensitários relativos às épocas dos papas Eugênio III (1080?-1153) e Adriano IV (1100?-1159). ${ }^{13}$

As dificuldades não cessavam aí. Essas compilações não formavam um índice total. Não eram tratados sistemáticos que demarcavam e destacavam o assunto. Sua elaboração não era movida pelo propósito de oferecer uma exposição completa, capaz de abarcar tudo o que era preciso saber sobre censos e prerrogativas temporais da Sé Romana. Seria precipitado vislumbrá-las como uma summa, nome que, na segunda metade do século XII, começava acompanhar aquelas obras capazes de reunir o conhecimento acumulado sobre uma disciplina,como a teologia. ${ }^{14}$ Aquelas compilações eram pontos de orientação. Seu texto evocava a presença de numerosos outros, cujo manuseio era um pré-requisito incontornável. Para compreender as referências de Albino ou aquilo que constava no livro censitário de Adriano, era preciso saber guiar os olhos pelas páginas da Collectio Canonum (Deusdedit, 1869) ${ }^{1}$, composta pelo cardeal Deusdedit (?-1100?) em 1086; pela coleção homônima concluída anos antes por Anselmo, bispo de Lucca (Cushing, 1998) (1035?-1086), além dos registros epistolários de papas como Gregório VII, Pascoal II (1070-118) e Adriano IV - o que formava um universo de centenas e centenas de cartas.

As atividades de seleção, transcrição, edição e
comentário dos manuscritos raramente foram
reconhecidas como uma prática social, isto é, como
filtros informacionais historicamente construídos

Ainda que a Gesta pauperis scholaris tenha oferecido um norte para o trabalho de compilação, fornecendo a maior parte do material e da inspiração que constituíram o Liber Censuum, o cardeal Savelli pelejou com textos ancestrais, dispersos e, muitas vezes, contraditórios. A tarefa exigiu dele muito mais do que encaixar as peças de um quebra-cabeça de registros escritos (scripta): Cêncio precisou remexer nos fragmentos de uma memória (memorialia) feita e desfeita no carrossel das décadas. Difícil resistir à ideia de que o próprio autor foi tomado pela consciência dessa tarefa, uma vez que as primeiras palavras

\footnotetext{
12Sobre as dificuldades para a datação do manuscrito 512 preservado na Bibliotéque Municipale de Cambrai, ver: Fabre (1889, p. 1-36).

${ }^{13}$ Além das próprias referências realizadas por Albinus, indicações sobre os livros censitários podem ser encontradas em: Duchesne (1981, p. 388-397).

${ }^{14} \mathrm{~A}$ elaboração de uma summa decorria de dois objetivos umbilicalmente ligados: emancipar um tema no bojo de um conjunto textual, dotando-o de referências específicas, e abranger integralmente o assunto em questão, constituindo um index geral do mesmo. Essa definição, bem como sua cronologia, foi fundamentada em: Chenu, 1957. Embora o exemplar mais conhecido desse tipo de forma literária seja a Suma Teológica de Tomás de Aquino (1225-1274), composta entre 1265 e 1273, alguns antecedentes marcam sua difusão na segunda metade do século XII, caso da Summa super Priscianum, composta por volta de 1150 por Pedro Helias (1100-1166?), clérigo que ensinara gramática e retórica em Paris, ou a Summa de sacramentis et animae consiliis, concluída por outro mestre parisiense, Pedro Cantor (?-1197), em 1187. Ver, respectivamente: Helias (1993); Cantor (1967)
} 
entregues por ele ao manuscrito foram estas: "inicia-se o livro dos censos da Igreja romana, composto pelo cardeal camareiro Cêncio, segundo registro dos antigos padres e diferentes recordações" (Fabre, 1889, p. 1). Provavelmente por essa razão, o Liber Censuum reúne textos que um olhar moderno consideraria heterogêneos ou até mesmo incongruentes: formados por quadros censitários diocesanos, os oito volumes iniciais são seguidos pelos Mirabilia, narrativas fabulosas sobre a cidade de Roma; após, dois volumes contêm as prescrições litúrgicas e cerimoniais do Ordo Romanus; outros dois foram reservados para crônicas pontifícias; por fim, quatro volumes foram dedicados a um cartulário. ${ }^{15}$

Quando se propôs a editar a obra do cardeal de Celestino III, Paul Fabre logo se deparou com uma realidade cabal: não se tratava de um "livro", no sentido moderno de um maço de páginas cuja materialidade encerrava o início, o meio e o fim de uma composição. Nada disso. Liber Censuum era o nome que identificava uma rede textual: uma obra aberta e multifacetada, cuja complexidade os séculos seguintes só fizeram aumentar. Novos livros foram acrescentados aos 18 volumes : - cinco pelo próprio Cêncio, após ser eleito papa Honório III, em 1216; mais de uma dúzia foi acrescida antes do fim do século XIII (Palazzi, 1984, p. 49-93). Enquanto a obra era assim expandida, as cópias se multiplicavam. Diversas versões do manuscrito surgiram pela Europa de tal modo que, séculos depois, próximo à virada para 1900, Fabre identificou quatro conjuntos de cópias: um grupo no Vaticano; outro, formado pelas cópias guardadas em bibliotecas de Roma; um terceiro com as versões existentes por toda Itália e, por fim, aquele de cópias existentes fora da península (Fabre, 1892, p.170-189).Os conjuntos formavam um total de 19 manuscritos. Todos eram cópias, elaboradas entre os séculos XIII e XVIII. O manuscrito original, escrito em 1192 sob os olhos de Cêncio, perdera-se. À primeira vista, era um cenário desolador. Cada cópia continha marcas de ampliações posteriores, tais como acréscimos de novos cadernos de fólios, interposição de atas e doações, registros tardios de vendas. Ao examiná-los, Fabre chegou a lamentar a ocorrência de tantas "anomalias" que imprimiam uma "falta de homogeneidade" às cópias (Fabre, 1892, p. 182-183). A passagem do tempo soterrara o registro original sob camadas de novas redações. Escavar os fundos arquivísticos e reencontrar o Liber em sua forma textual primitiva, originária, seria uma tarefa árdua. Todavia, nessa aparente "falta de pureza", estava contida uma singularidade medieval: o caráter aberto da forma literária constituída pelo livro dos censos. Como dissemos há pouco, não se tratava de uma obra fechada, unívoca, já concluída no momento em que foi entregue por Cêncio. Produto tanto da memória quanto da letra escrita, a compilação de 1192 era um texto em movimento. As matérias contidas em seus pergaminhos poderiam ser modificadas, recriadas, afinal, era preciso preservar as informações oriundas de diferentes fontes de autoridade: as escritas e as não-escritas (pessoais, orais). A suposta "ausência de ordem" era, na realidade, o vestígio deixado pela presença dos atributos pessoais como fundamento da dinâmica institucional. Mudavam as

15Sobre a caracterização tipológica dos 18 volumes primitivos, ver: Boespflug (2002, p. 1041-1042). 
personas, mudavam os registros do que precisava ser conhecimento. As rendas, cobranças e isenções realizadas pela Sé de Roma não escapavam à realidade de cultura medieval, magistralmente demonstrada por Paul Zumthor: o texto seguia o compasso da vida, não era seu maestro (Zumthor, 1991). ${ }^{16}$

Vistas em conjunto, as cópias tinham algo a dizer ao historiador. Eram "fontes históricas" de um funcionamento patrimonial específico, distante no tempo das lógicas burocráticas da modernidade.Precisamente aqui,constatam-se os efeitos do acionamento do método de crítica documental. Conforme havia ensinado Fustel de Coulanges ${ }^{17}$, Fabre lançou sobre o conjunto de manuscritos uma interrogação técnica, mas decisiva: qual versão era mais próxima do original? A pergunta expressava uma exigência: era preciso classificar os manuscritos, pois um deles era o arquétipo do qual derivavam os demais. A atuação de Fabre para solucionar esse enigma foi impecável. Seu passo a passo foi tão seguro quanto rigoroso. Primeiro, passou em revista as circunstâncias de preservação de cada cópia: que instituições as abrigavam, quais registros oficiais havia sobre cada uma, quem as deteve e em quais atos de transmissão e doação elas foram envolvidas. Detalhista, ele vasculhou os manuscritos desde a superfície: tamanho dos fólios, cores das letras, estilos caligráficos, composição das margens, usos de espaços. Em seguida, a etapa mais difícil, a comparação sistemática do conteúdo (Fabre, 1892, p.170-227). A cada fase de crítica documental, Fabre credenciava o papado do século XII como objeto para a escrita de uma história concebida como "ciência pura, uma ciência como a física ou como a geologia, [...] que visa apenas encontrar fatos, descobrir verdades, [...] de modo tão imparcial, tão independente e tão impessoal quanto todas as demais ciências" (Coulanges, 2003, p. 305).

Trilhadas as etapas, o veredito chegou sem rodeios. Das 18 versões, 13, realizadas sobre papel, não passavam de cópias do texto preservado sob o código 229 na Biblioteca Riccardi, em Florença. Restavam seis versões, que tinham em comum o fato de terem sido confeccionadas sobre pergaminho: o manuscrito Vaticano 8486; os manuscritos Riccardi 228 e 229; dois manuscritos do Arquivo Vaticano, códigos XV1 e XXXV18; e, por fim, o Parisinus 4188 da Biblioteca Nacional da França. Realçando minuciosos padrões de variação na disposição das matérias, em tabelas e em frases fragmentadas, Fabre lavrou a conclusão: composto em algum momento entre 1192 e 1236, o Vaticanus 8486 era a mais antiga reprodução direta do texto concebido pelo cardeal Savelli. Era, portanto, o arquétipo de todas as versões conhecidas. As outras 17 cópias eram filiações de um único manuscrito - daquele manuscrito (Fabre, 1892, p. 189190). De modo magistral, Fabre desfizera o impasse. Ele depurara a genealogia dos textos, reencontrando o ancestral comum. O Vaticanus 8486 foi declarado

\footnotetext{
${ }^{16}$ Ver também: Carreto (1996).

${ }^{17}$ Além de dedicar uma parcela de sua produção ao "mestre Fustel de Coulanges", Paul Fabre foi influenciado pela leitura de Histoire des institutions politiques de lancienne France, que se tornaria um modelo analítico para o então aluno da École Normale Supérieure. Ver: Coulanges (1875). Além desse significado biográfico, a obra de Coulanges se tornou paradigmática para a operação historiográfica na França da segunda metade do século XIX. Ver: Hartog (2003)
} 
o "exemplar primitivo e original do Liber Censuum" (Fabre, 1892, p. 200). Seu conteúdo foi transcrito; a redação latina foi modernizada com pontuação; a fluência textual compassada com espaçamentos. $\mathrm{O}$ texto editado ganhou a forma de páginas idênticas que, povoadas por incansáveis notas de rodapé, foram impressas, formando o primeiro de dois tomos - o autor, todavia, não viveria para concluir o trabalho, encerrado em 1910 por Louis Duchesne (Kirsch, 1902, p. 391).Os círculos acadêmicos saudaram Fabre como autor de uma pequena proeza: removidos da guarda privilegiada de arquivos e das bibliotecas, "os registros originalmente compilados por Cêncio Savelli" podiam ser comprados em uma esquina de Paris ou de Londres. ${ }^{18}$ Até então pouco examinada, a compilação seria laureada como uma das fontes históricas mais preciosas já herdadasda Idade Média. Ela se tornou uma das principais colunas de sustentação de estudos como Études sur l'administration de Rome au Moyen Âge (7511252), de Louis Halphen (Halphen, 1907). Meio século depois,Jean Rousset de Pina o batizaria como "o mais efetivo instrumento e o mais significante documento da centralização eclesiástica na Idade Média” (Pina; Foreville, 1953, p. 246; Robinson, 1990, p. 260-261). Todavia, naquele mesmo instante, outro resultado foi alcançado: a forma aberta do Liber Censuum foi desfigurada pela edição moderna. A publicação produziu uma metamorfose. Encapsulado em umaforma típica da cultura livresca contemporânea, o conteúdo deixou de ser um ponto nodal de uma memória administrativa fragmentada e em contínua reformulação e se transformou em uma referência autônoma, independente,cujas páginas bastavam para retratar certo estado da vida material papal. O que antes era um ponto de captura de vastos repertórios de reminiscências (memorialia) sempre em movimento, circulava, agora, como um livro de contabilidade. As qualidades de "plural" e "inacabado" cederam espaço para uma nova grandeza, singular e fechada sobre si. "O" Liber Censuum passava a ser visto como depositário de uma lógica de governo familiar, supostamente orientada para produzir a unidade e a totalidade de um quadro institucional. Antes parte de um fluxo vivo de informações, o texto manuscrito passou a ser visto como um fenômeno externo aos homens do século XII, uma espécie de instrumento de monitoramento máximo, uma plataforma de observação burocrática. Ou, simplesmente, como um lugar: como o ponto central onde Cêncio se posicionara para lançar um olhar panóptico sobre as rendas e prerrogativas temporais da Santa Sé. O Liber Censuum era agora um índice de matérias institucionais, um sumário redigido por um olhar soberano.

Em termos epistemológicos, o trabalho de Paul Fabre produziu uma fundação conceitual. Isso não quer dizer que ele "inventou" a noção de "Estados Papais". Como vimos, ela o precedia. A fundação em questão não pode ser reduzida a uma ruptura ou à criação de um "marco zero" na teoria científica. Não se trata de um jogo de binômios do tipo "ruptura versus continuidade", mas da

18 "Paul Fabre terá, portanto, o direito de contar com o reconhecimento do mundo erudito, pelo simples fato de ter estabelecido, após coligar todos os manuscritos conhecidos, um texto de tão alto valor". Berger (1890, p. 536). Para outras avaliações da recepção da edição moderna, ver: Bateson (1893, p. 756-758). 
transformaçãodo discurso a respeito de certo fenômeno através do deslocamento dos significados existentes. Conforme definiu o semiólogo Eliseo Verón, "uma fundação não é senão um sistema de diferenças entre sistemas de relações, relações que os discursos contraem com as condições que os sustentam e explicam enquanto produtos de uma prática significante que se desenrola na História" (Verón, 1980, p. 122). Sustentado pelo aniquilamento do poder civil da Igreja romana, que transcorria após 1850, o discurso sobre o poder temporal do papado foi refundado por sentidos deslocados pela moderna edição do Liber Censuum. Expliquemos um pouco mais essa ideia.

\section{Território e soberania: conjugando o passado medieval}

A edição do Liber Censuum dotou o conceito de "monarquia papal medieval" de um fundamento empírico até então pouco evidente. A partir daquele momento, essa expressão passou a contar com lastro científico. Já não era mais um fraseado de certa corrente de pensamento ou uma ideia colocada em jogo por polêmicas moralizantes. Tratava-se de uma realidade demonstrada objetivamente: seus vestígios foram reunidos, verificados e depurados através de um processo crítico criterioso, metódico e exposto claramente. Aquela expressão deixou de ser uma construção intelectual. Era um nome sustentado por uma autêntica "fonte histórica".

\section{A forma aberta do Liber Censuum foi desfigurada pela edição moderna. A publicação produziu uma metamorfose}

Esse processo, no entanto, não se restringiu à nova forma assumida pelo Liber Censuum. Ele foi completado pelo ambiente interpretativo criado por Paul Fabre. Em 1892, com o processo editorial ainda em curso, pouco após o aparecimento da primeira parte dos dois tomos planejados, Fabre trouxe a público o Étude sur le Liber Censuum de l'Église Romaine. Tratava-se de sua tese de doutorado, submetida à Faculdade de Letras de Paris. O estudo era uma obra introdutória ao processo editorial. Lá, estavam pormenorizadas as etapas de descrição, classificação e filiação dos manuscritos, formando um relatório de aplicação do método de crítica documental, mas havia mais. Além da "perspicácia da crítica, da clareza e da sobriedade da exposição" (Fournier, 1893, p. 542), a nova publicação trazia consigo uma teoria específica sobre o "censo apostólico". Destilada nas longas notas de rodapé incluídas no primeiro volume da versão moderna do Liber Censuum, essa teoria exerceria influência determinante sobre o significado atribuído ao conteúdo do manuscrito. De fato, ela passou a emoldurar a leitura. 
Desde a primeira linha, Fabre insistiu: quem pousasse os olhos sobre o Liber Censuum deveria perceber que não encarava outro cartulário medieval. A compilação realizada pelo cardeal Savelli era um registro único, inédito (Fabre, 1892, p. 7). Isso se devia ao fato de o texto resultar de uma transformação ocorrida a partir do século XI, quando "assistimos a uma reorganização completa [da organização da Igreja de Roma], sob a poderosa iniciativa do subdiácono Hildebrando" (Fabre, 1892, p. 11).A referência era conhecidíssima. Tratava-se de uma alusão às décadas de 1050 e 1060, quando Hildebrando de Soana - eleito papa Gregório VII em 1073 - esteve à frente do poder papal. Fabre corroborava a opinião corrente de que Hildebrando havia sido o protagonista da ascensão de uma nova forma de governo pontifício, caracterizado por um controle mais rigoroso sobre as rendas e bens apostólicos.Neste, como em muitos outros aspectos, a segunda metade do século XI configurava uma ruptura histórica, fazendo jus ao solene título de "Renascimento Gregoriano".

Uma obra como o Liber Censuum dificilmente seria possível ou faria sentido antes da "Renascença Gregoriana" - assegurou Fabre. O modo de pensar nele contido condensava uma atitude teocrática: "remover do esquecimento e afirmar solenemente os direitos e rendas realizados pela Santa Sé". Após sobreviver ao chamado "século de ferro" - o período de 950 a 1050 -, quando a ordem eclesiástica teria sucumbido a uma anarquia de desmandos laicos instalada pelo feudalismo, o papado transformara a restauração dos patrimônios eclesiais em uma política de afirmação da autoridade sacerdotal. Um novo espírito animava a conduta da cúpula romana. Os propósitos acalentados por essa elite eclesiástica renovada tornaram insuficientes as técnicas de elaboração de inventários de gestão dominial, documentos carolíngios designados "Polípticos"19. Após o "triste eclipse do papado [no século X], tentou-se substituir [aforma de registro], com a ajuda dos arquivos pontificais" (Fabre, 1892, p. 23-24).

Ao distinguir o Liber Censuum dos polípticos, Fabre assinalava a singularidade do documento tanto quanto do próprio trabalho como historiador. Há décadas, edições e estudos sobre os polípticos surgiam nas prateleiras das livrarias europeias; alguns já haviam se tornado referências consagradas junto aos círculos eruditos da época: caso do Polyptyque de L'Abbé Irmion, publicado em 1836-1844 por Benjamin Guérard (Guérard, 1836-1844). A edição do Liber Censuum era um caso à parte, pois consistia em uma coleção de registros elaborada por um proprietário incomum, excepcional - era o que assegurava 0 próprio editor. Afinal, a "Renascença Gregoriana" teria imposto à Igreja romana uma condição senhorial diferenciada. Existindo no seio do mundo feudal, o papa atuava como grande senhor, exigindo o cumprimento anual de serviços e rendas. Todavia, o homem que se sentava na cátedra de Pedro encimava uma instituição particular. A Igreja governada por ele havia sido alçada ao primeiro plano da vida política cristã pela fundação dos domínios papais, ainda

19Sobre conceituação, abrangência e constituição dos "polípticos", ver: Verhulst (2002); Rouche (1993); Guéralt (2003). 
nos tempos de Carlos Magno. O bispado romano não era parte de um patrimônio alheio, como se integrasse o reino ou império de outro, mas detentor de prerrogativas temporais autônomas. Graças a essa condição, aquele bispo usufruía um "direito eminente de propriedade", percebido através da cobrança de censos (Fabre, 1892, p.iii-iv). Nos séculos IX e X, enquanto abades e bispos pelejavam com a elaboração dos polípticos, os sucessores de São Pedro lidavam com prerrogativas políticas maiores. A constatação fazia mais sentido se não fossem perdidas de vista as consequências de um episódio da história monástica: a fundação de Cluny. A carta de fundação do mosteiro beneditino revelava as características originais do domínio espacial protagonizado pelo papado. Assim, Fabre prosseguiu à argumentação.

\section{Após sobreviver ao chamado "século de ferro," o papado transformara a restauração dos patrimônios eclesiais em uma política de afirmação da autoridade sacerdotal}

À época da fundação, em 910, o duque Guilherme da Aquitânia (875-918), renunciou aos direitos de propriedade sobre as terras concedidas à abadia beneditina e evocou o bispo de Roma como protetor daquelas paisagens. Gesto tradicional, antigo: "até aqui nada de novo" (Fabre, 1892, p. 54), lembra Fabre. No entanto, os termos dessa concessão eram inéditos. Conforme estabeleceu o duque, as terras doadas estavam removidas não só do seu domínio, mas de qualquer domínio temporal que não aquele exercido pelo papa. Exceto ele, ninguém teria voz sobre o patrimônio cluniacense, nem mesmo os filhos do ilustre patrono, sequer o monarca, tampouco outros príncipes ou imperadores deste mundo. Além disso, o pontífice não poderia parcelar, diminuir, alienar ou doar aquelas terras em benefício de quem quer que fosse, sob pena de maldição divina (Fabre, 1892, p 54). ${ }^{20}$ Incisivos, os termos da doação convertiam "a abadia de Cluny em uma propriedade inalienável da Santa Sé". Embora fincada na Gália, a abadia foi fundada como conjunto espacial externo à autoridade do rei local. À medida que a congregação beneditina se expandiu pela Cristandade, multiplicando as localidades implicadas naqueles termos, novas casas e patrimônios foram igualmente vinculados a essa proteção autônoma, inalterável e exclusiva delegada ao papado desde as origens. A conclusão extraída por Fabre não deixa margens para maiores dúvidas: “o papa possuía sobre todas as terras da abadia um domínio eminente que se exprimia pelo pagamento do censo". As rendas devidas a Roma eram práticas sociais do reconhecimento de uma unidade espacial politicamente fundamentada: "de fato, [com o estabelecimento de Cluny], concedeu-se à Santa Sé, acima de tudo, um meio de exercer uma proteção eficaz, com o domínio eminente do apóstolo criando

20 Preservamos, na redação do parágrafo, o sentido dos termos empregados por Fabre. Não se trata, portanto, de uma paráfrase do documento histórico - embora seu conteúdo esteja transcrito no estudo. 
menos um direito e sim uma obrigação". Somada à existência dos domínios apostólicos, a vinculação patrimonial cluniacense consolidava uma posição de poder incomum: "a autoridade da Santa Sé se afirma e se desenvolve pelo próprio desenvolvimento da instituição” (Fabre, 1892, p. 58).

$\mathrm{O}$ advento de Gregório VII teria conduzido esse processo de institucionalização a uma nova fase histórica. Mesmo sem introduzir grandes modificações no cenário de doações monásticas vinculadas à proteção apostólica entre 900 e 1070, seu pontificado apurou a consciência das multifacetadas elites cristãs acerca do significado político dessas doações. Os privilégios foram recrutados por ele como meios para reforçar a autoridade pontifícia em meio ao turbulento contexto da "luta pelas investiduras". A fixação do papado como instância máxima para assegurar a integridade patrimonial de numerosos estabelecimentos religiosos transformava a Igreja romana em um tipo de "instituição que se generalizava e se estendia" (Fabre, 1892, p. 68). Diferente de qualquer corte episcopal feudal, o palácio apostólico era um centro que irradiava prerrogativas decisórias para muito além de seus limites diocesanos ou provinciais. Ainda que Gregório concebesse a si mesmo como o imitador do passado apostólico, o restaurador de um modo de vida primitivo, em cuja mente "reformar a Igreja" queria dizer lutar contra a inovação e os costumes trazidos pelo tempo, suas ações modificaram a organização e a abrangência do poder papal. Sua atuação contra o que considerava serem "invasões do espírito laico" nos assuntos clericais implicava reconhecer certo direito de propriedade: mesmo quando singularmente mitigado, o pertencimento de um bem ao vigário de Pedro excluía da realidade da posse quem exercia somente o domínio útil. Ou seja, o usufruto ou a ocupação de um bem não deveria ser confundido com a posse, detida somente por aquele que conservava a livre disposição do domínio eminente, a própria Santa Sé (Fabre, 1892, p. 70).

Essa realidade foi consolidada nos pontificados seguintes, especialmente no de Urbano II (1042?-1099). Após examinar os registros de doação acumulados durante a passagem deste prior de Cluny pela Santa Sé, Fabre afirmou: "a maior parte dos atos estudados se ocupam unicamente de proteger os monastérios contra toda tentativa de absorção ou de desmembramento". Na época feudal,quando a posse era identificada com diversas práticas de uso de um bem, produzindo "proprietários" em efeito cascata, a voz papal comunicava a compreensão inusitada de que certos patrimônios estavam submetidos a Roma de modo direto, integral e exclusivo. Isto é, cada palmo de terra entregue à proteção apostólica era "uma rica presa que o papa subtraía à avidez dos grandes deste mundo, como reis, marqueses, bispos ou condes” (Fabre, 1892, p. 73).

Na passagem para o século XII,a liberdade desses monastérios censitários ganhou uma definição mais estrita e, ao mesmo tempo, mais completa. Generalizou-se a opinião de que a Cúria papal assegurava uma liberdade extraordinária, que destoava das conhecidas garantias de imunidade fiscal. Por isso, tal condição ganhou um epíteto especial de "liberdade romana" (libertas Romana). Graças aos reformadores, “amigos e partidários de Gregório VII”, tal definição adquiriu conteúdo social, redefinindo as relações de propriedade 
dos patrimônios eclesiásticos (Fabre, 1892, p. 76-80).À medida que as décadas avançaram, os medievais adquiriram consciência das relações políticas que regiam essas relações. Em meados do século XII, despontaram na documentação as marcas de uma oposição entre as noções de libertas Romana e protectio Romana. Após figurarem como sinônimos por muito tempo, as duas ideias se separaram. A linguagem finalmente capturara uma tensão social: os abades e bispos que buscavam a liberdade de suas casas acabavam, com frequência, enredados em uma relação de submissão e controle (Fabre, 1892, p. 101).Sob a perspectiva de um número crescente de prelados, a proteção oferecida por Roma não correspondia ao que nomeava a palavra "liberdade". Talhada com refinamentos jurídicos da época de Graciano (?-1160?), a distinção marca, segundo Fabre, a culminância do poder papal. O histórico de conflitos envolvendo as cláusulas de isenções reclamadas por mosteiros evidenciara o quanto a liberdade romana era o veículo de difusão do domínio apostólico sobre terras distantes ao patrimônio de São Pedro. No momento em que o cardeal Cêncio Savelli compôs o Liber Censuum, em diversos pontos da Cristandade, formava-se uma percepção de que a expressão libertas Romana - divulgada como símbolo de emancipação espiritual - poderia ser traduzida por in jus et proprietatem beati Petri - "vinculada ao direito e propriedade do bem-aventurado Pedro" (Fabre, 1892, p. 114-147). Quando se tratava do papado, era preferível buscar a proteção à liberdade.

Os pagamentos anuais remetidos para a cátedra de Pedro formalizavam uma relação de subordinação. Em Roma, a palavra liberdade significava "uma condição sobre a terra, resultante do direito eminente de propriedade possuído pelo apóstolo Pedro" (Fabre, 1892, p. 147).Conjugando a ideia de liberdade desse modo, o movimento reformador liderado por Gregório VII converteu o clero papal em arquiteto de práticas políticas estranhas ao mundo feudal; na realidade, opostas a ele, mas que cresceriam com o passar dos séculos até se fixarem como metas de todos os poderes instituídos: a unidade territorial e a centralidade administrativa. Tal orientação de leitura englobou a edição do Liber Censuum. Através de um enxame de notas de rodapé - além, claro, da própria publicação do Étude - , ela colonizou a versão contemporânea do texto medieval. Com isso, Fabre reeducou o olhar dos historiadores. Os registros escritos compilados pelo cardeal Savelli figuravam como a prova física da atuação do papado como um núcleo político propagador de uma gestão fundiária caracterizada pela unidade territorial e a inviolabilidade jurídica — isso em uma época em que homens e terras eram regidos pela memória dos costumes e por laços pessoais de partilha. Em pleno século XII, o papado já era uma monarquia que qualquer homem moderno poderia reconhecer.

\section{Repercussões historiográficas: consumando a fundação conceitual}

A partir de então, o lastro científico do trabalho de Fabre levaria os estudiosos a esperarem por essa conclusão. Não só pelas evidentes extensões fundiárias em questão, mas, sobretudo, porque o Liber Censuum permitia ver o primado 
petrino em ação: as relações de propriedade materializadas no censo apostólico existiam em função de uma autoridade sem igual entre as igrejas cristãs, a única capaz de coroar imperadores, erigir tronos e dispensar coroas. Após o século XI, a Santa Sé teria se tornado uma instituição "investida de uma verdadeira magistratura", a portadora de um "direito suprarreal (supra-régalien)" (Fabre, 1892, p. iv) que entrou em declínio somente com o papa Bonifácio VIII (1230-1303). As rendas e serviços exigidos pelo papado conservavam algo mais que as características de um "direito privado" ou "feudal".

Combinados, o domínio espacial singular e a superioridade do primado petrino permitiriam chegar a uma conclusão forte. Refratado sob o prisma da moderna edição do Liber Censuum, o papado medieval aparece como protagonista de dois ideais vitais aos estados oito centistas: a unidade territorial e o governo soberano. Essas categorias refluíram para a compreensão histórica, ambas naturalizadas como dados objetivos, como as provas cientificamente demonstradas de um processo conhecido como "institucionalização do governo papal”. O próprio Fabre detalhou diversas etapas deste processo, que teria transcorrido sem graves reveses entre 1050 e 1300. Sua incansável rotina de pesquisas cobriria, inclusive, contextos posteriores, vinculando outras épocas a essa história de ascensão política do papado,como em Le Patrimonie de l'Église Romaine dans les Alpes Cottiennes; Un Registre Caméral du cardinal Albornoz en 1364: documents pour servir à l'histoire du Patrimonium Beati Petri in Tuscia au quatorzième siècle; Registrum Curiae Patrimonii Beati Petri in Tuscia; e ainda La Perception du Cens Apostolique dans l'Italie Centrale en 1291 (Fabre, 1884, p. 383-420; 1887; 1889, p. 3-24; 1890, p. 369-383). Formados como leitores assíduos de Paul Fabre, os estudiosos do século XX se encarregariam de entabular a equação: institucionalizar é sinônimo de centralizar e unificar. Assim pensaram, por exemplo, Gabriel Le Bras (Le Bras, 1959, p. 52-178), Raffaello Morghen (Morghen, 1945; Morghen, 1962, p. 105-177) e Walter Ullmann (Ullman, 1955) - autores que carregam a reputação de "clássicos historiográficos". Os ecos dessa compreensão podem ser ouvidos ainda hoje, no século XXI. Basta ler, por exemplo, The Crisis of the Twelfth Century: Power, Lordship, and the Origins of European Government para reencontrar a conclusão sacada por Fabre há mais de cem anos: "o Liber Censuum era um novo ponto de partida, [...] seu conteúdo rapidamente superou os propósitos fiscais e [...] testemunhou uma nova concepção do poder papal" (Bisson, 2009, p. 418-419).

Entre os séculos XI e XIII, a Igreja romana foi transformada em uma instituição cuja superioridade realizava-se sujeitando a elite eclesiástica e sufocando a autonomia das relações locais. A administração dos "Estados Papais" teria assinalado o apogeu dessa mudança, que, supostamente, fez do bispo romano um monarca eclesiástico. As obras que encamparam essa abordagem formam uma bibliografia valiosa, que reúne alguns dos mais conceituados medievalistas. Caso de The Papal State in the Thirteenth Century, concluído por Daniel Waley em 1961 (Waley, 1961); de The Lands of Saint Peter: the Papal State in the 
Middle Ages and the Early Renaissance, síntese lançada por Peter Partner em 1972 (Partner, 1972); oude Scrinium y Palatium: la formation de la bureacratie pontificale, capítulo de um estudo de fôlego publicado por Pierre Toubert em 2004 (Toubert, 2006). A fortuna do conceito foi maior na historiografia inglesa e norte-americana, onde passou a preponderar sobre as noções de teocracia papal $^{21}$ e hierocracia pontífica ${ }^{22}$ - dominantes nos estudos influenciados porintelectuaisfranceses e mediterrânicos.

Todavia, coube a Collin Morris o mérito por ter consagrado essa conceituação. Em 1987, véspera do centenário da publicação da primeira parte da edição do Liber Censuum, esse professor emérito da Universidade de Southampton lançou The Papal Monarchy: the Western Church from 1050 to 1250 (Morris, $2001)^{3}$. À primeira vista, a obra consistia em uma síntese do estado da arte historiográfica, com suas páginas redigidas para formar um panorama das visões vigentes entre os historiadores a respeito do papado e suas relações como o Ocidente durante a Idade Média Central. Filho dileto da tradição britânica em compor "histórias gerais", o livro foi aclamado por sua visão de conjunto: "lê-lo é como realizar um curso sério de história eclesiástica sobre o período" (Brentano, 1992, p. 1014). Mas havia mais. Havia uma inovação importante, que surgia disfarçada dos trajes habituais de uma história geral. A adoção da perspectiva de síntese - uma escolha por vezes depreciada, tida como uma opção que simplifica o passado e castra a capacidade de formular teses criativas - produziu uma inflexão historiográfica decisiva.

\section{A administração dos "Estados Papais" teria assinalado o apogeu dessa mudança, que, supostamente, fez do bispo romano um monarca eclesiástico}

O surgimento da "monarquia papal medieval" deixava de ser parte da história da Igreja romana e passava a englobá-la. The Papal Monarchy amplificou o legado de Fabre, elevando-o a uma nova grandeza: o processo de institucionalização do papado abarcava múltiplas temporalidades e facetas da vida medieval. Os padrões da mudança social, as dinâmicas da religiosidade, a movente cartografia das instituições cristãs, os deslocamentos das fronteiras da adesão e da dissidência e até as tensões intelectuais da vida ocidental: segundo Morris, tudo confluía para o apogeu da "monarquia papal". O conceito, até então aplicado em sentido estrito - isto é, designando práticas e ideias de controle, gestão e administração - , era empurrado para um salto epistemológico: agora, ele recobria o curso de uma totalidade social no tempo. As ramificações da

\footnotetext{
${ }^{21} \mathrm{O}$ apogeu da noção de "teocracia papal" no medievalismo francês e francófilo pode ser assinalado com a publicação de: Pacaut (1957). Ver ainda: Dietler (1966, p. 93-109); Pacaut (1976); Théry (2010, p. 17-31).

${ }^{22} \mathrm{~A}$ noção de "hierocracia pontifícia" se distingue por conferir maior relevo histórico ao pensamento jurídico e político e por recobrir, principalmente, a chamada Idade Média Tardia. Para uma visão panorâmica sobre o tema, ver o clássico estudo: Barbosa (1992, p. 149-165).
} 
abordagem eram significativamente diferentes daquelas presentes em estudos como The theory of papal monarchy in the 13th century: the contribution of the canonists (Wattt, 1965) e Pope and Bishops: the papal monarchy in the twelfth and thirteenth centuries (Pennington, 1984), estruturadas a partir de recortes monográficos jurídicos. Ombreando conceitos de maior tradição e envergadura sociológica, tais como civilização e sociedade, a expressão "monarquia papal" figurava agora como uma categoria de periodização: eis o nome cabível a uma fase inteira da história ocidental. Manejando-a, o historiador poderia elaborar uma "narrativa da história religiosa do Ocidente latino entre 1050 e 1250" (Morris, 2001, p. 6).

Levadas de roldão por essa amplificação conceitual, as premissas oitocentistas da progressiva unificação territorial e da centralização decisória soberana, alojadas nas páginas da moderna edição do Liber Censuum, atingiram a máxima expressividade do óbvio, de um dado "simplesmente real". Empiricamente demonstrada, conceitualmente elaborada e acolhida como uma terminologia geral da história ocidental, o conceito de "monarquia papal" se impôs como limite da compreensão histórica. Ultrapassá-lo seria desautorizar a realidade e colocar-se porta afora da cientificidade. Assim,o conceito fez do passado fiador incondicional dos valores políticos modernos.

\section{Referências bibliográficas}

Acta et decreta sacrosancti et oecumenici Concilii Vaticani die 8. decembris 1869 a ss. d. n. Pio p. IX inchoati. Friburg: Sumtibus Herder, 1871, p. 180-184.

AFFRE, Denis Auguste. Essai historique et critique sur la suprématie temporelle du Pape et de l'Église. Amiens: Caron-Vitet, 1829.

ALIX, Abbé C. Études Théologique sur le Pouvoir Temporel du Pape. Paris: Adrien Le Clere, 1860. BARBOSA, João Morais. Fundamentos Teóricos da Hierocracia no Pensamento Político da Baixa Idade Média, Revista da Universidade de Coimbra, vol. 37, p. 149-165, 1992.

BATESON, Mary. Étude sur le Liber Censuum de l'Église Romaine by Paul Fabre, The English Historical Review, vol. 8, n. 32, p. 756-758, 1893.

BEALES, Derek; BIAGINI, Eugenio F. Il Risorgimento e l'unificazione dell'Italia, Bologna: il Mulino, 2005.

BERGER, Élie. Le Liber censuum de l'Église romaine, ler fascicule, par Paul Fabre, Bibliothèque de l'École des Chartes, vol. 51, n. 51, p. 536-538, 1890.

BISSON, Thomas. The Crisis of the Twelfth Century: power, lordship, and the origins of European Government. Princeton: Princeton University Press, 2009.

BLUMENTHAL, Uta-Renate. Cardinal Albinus of Albano and the Digesta pauperis scolaris Albini: Ms. Ottob. lat. 3057, Archivum Historiae Pontificiae, vol. 20, p. 7-49, 1982.

BOESPFLUG, Thèrese. "Liber Censuum”. In: LEVILLAIN, Philippe (Dir.). Dictionnaire historique de la Papauté. Paris: Fayard, 2002, p. 1041-1042.

BRAS, Gabriel Le. Institutions Ecclesiastiques de la Chrétienté Médiévale. Paris: Bloud \& Gay, 1959. BRENTANO, Robert. The Papal Monarchy: The Western Church from 1050 to 1250. Speculum, vol. 67, n. 4, 1992.

CANTOR, Pedro. Summa de sacramentis et animae consiliis. Louvain: Nauwelaerts, 1967. Ed. Jean-Albert Dugauquier. Vol. 3.

CARRETO, Carlos Clamote. Figuras do silêncio: do inter/dito à emergência da palavra no texto medieval. Lisboa: Estampa, 1996. 
CENNI, Gaetano. Monumenta Dominationis Pontificiae sive Leonis tertii. Tomo 2. Roma: Typographia Palladis, tomo 2, 1761.

CHENU, Marie-Dominique. La théologie au douzième siècle. Paris: J. Vrin, 1957.

COULANGES, Numa Denis Fustel de. Histoire des institutions politiques de l'ancienne France. Paris: Hachette, 1875.

COULANGES, Fustel de. A história, ciência pura. In: HARTOG, François, O século XIX e a história: o caso Fustel de Coulanges. Rio de Janeiro: Editora da UFRJ, 2003.

COSTIGAN, Richard F. The Consensus of the Church and Papal Infallibility: a study in the background of Vatican I. Washington: The Catholic University of America Press, 2005.

CUSHING, Kathleen. Papacy and law in the Gregorian Revolution: the canonist work of Anselm of Lucca. Oxford: Oxford University Press, 1998.

DENZINGER, Heinrich; SCHÖNMETZER, Adolf. Enchiridion symbolorum definitionum et declarationum de rebus fidei et morum, Freiburg, Basel. Rome \& Vienna: Herder, 1997.

DEUSDEDIT, Cardeal. Collectio canonum. In: PIO Martinucci(Ed.), Deusdedit Presbyteri Cardinalis Tituli Apostolorum Eudoxia Collectio Canonum. Veneza: Typographia Aemiliana, 1869.

DIETLER, Marcel. La théocratie pontificale et Innocent III, Echos de Saint-Maurice, tomo 64, 1966, p. 93-109.

DUCHESNE, Louis. (Ed.) Liber Pontificalis . Tomo 2. Paris: Éditions des Boccard, 1981, p. 388-397. FABRE, Paul. Étude sur le Liber Censuum de l'Église romaine. Paris: Ernest Thorin, 1892.

FABRE, Paul. l'Italie Centrale en 1291", Mélanges d'archéologie et d'histoire, vol. 10, n. 10, p. 369-383, 1890.

FABRE, Paul. (Ed.) Le Liber Censuum de l'Église Romaine. Paris: Ernest Thorin, Vol. 1, 1889.

FABRE, Paul. Le Polyptyque du Chanoine Benoit, Travaux \& Mémoires des Facultés de Lille, tomo 1, n. 3, 1889.

FABRE, Paul. Le Liber Censuum de l'Église Romaine. Paris: Ernest Thorin, 1889, vol. 1.

FABRE, Paul. Le Patrimonie de l'Église Romaine dans les Alpes Cottiennes, Mélanges d'archéologie et d'histoire, vol. 4, n. 4, p. 383-420, 1884.

FABRE, Paul. Le polyptyque du Chanoine Benoit, Travaux \& Mémoires des Facultés de Lille, tomo 1, n. 3, 1889, p. 1-36.

FABRE, Paul. Registrum Curiae Patrimonii Beati Petri in Tuscia, Mélanges d'archéologie et d'histoire, vol. 9, n. 9, p. 3-24, 1889.

FABRE, Paul. Un Registre caméral du cardinal Albornoz en 1364: documents pour servir à l'histoire du Patrimonium Beati Petri in Tuscia au quatorzième siècle. Paris: Philippe Cuggiani, 1887. FIORENTINO, Carlo Maria. Dalle Stanze del Vaticano: il venti settembre e la potesta della S. Sede, 1870-1871, Archivum Historiae Pontificiae, vol. 28, p. 285-333, 1990.

FOURNIER, Paul. Étude sur le 'Liber Censuum' de l'Église romaine, par Paul Fabre, Bibliothèque de l'École des Chartes, vol. 54, n. 54, p. 542, 1893.

GERRITY, Frank. Joseph Ripley Chandler and The Temporal Power of the Pope, Pennsylvania History, vol. 49, n. 2, p. 106-120, 1982.

GOSSELIN, Jean Edme Auguste. Pouvoir du pape au moyen âge ou Recherches historiques sur la souveraineté temporelle du Saint-Siége et sur le droit public du Moyen Âge, 2a ed., vol. 2. Louvain: C. J. Fonteyn, 1845.

GUÉRALT, Setephane. Les polyptyques caroligiens, disponível em: www.polycarolingien.free. fr, Acesso: em 22 fev. 2015.

GUÉRALT, Setephane. Le vocabulaire économique et technique des polyptyques, Histoire \& Mesure, vol. 18, n. 3/4, 2003. Disponível em: www.histoiremesure.revues.org/833. Acesso em: 22 fev. 2015.

GUÉRARD, Benjamin. Polyptyque de l'Abbé Irminon: ou Etat des terres, des revenus et des serfs de l'Abbaye de Saint-Germain-des-Prés. 2 tomos. Paris: Imprimiere Royale, 1836-1844.

HALPHEN, Louis. Études sur l'administration de Rome au Moyen Âge (751-1252). Paris: H. Champion, 1907. 
HARTOG, François. O século XIX e a história: o caso Fustel de Coulanges. Rio de Janeiro: Editora da UFRJ, 2003.

JAFFÉ, Philippus; et al. Regesta Pontificum Romanorum ab condita Ecclesia ad annum post Christum Natum 1198 ad anum 1304 (Ed.). Leipzig: Veit, 1885-1888.

KERTZER, David I. Prisoner of the vatican: the Popes, the Kings, and Garibaldi's Rebels in the struggle to rule Modern Italy. New York: Houghton Mifflin Harcourt, 2004.

KERTZER, David I. The Pope and Mussolini: the secret history of Pius XI and the Rise of Fascism in Europe. Oxford, Oxford University Press, 2014.

KIRSCH, J. P. Notes sur deux fonctionnaires de la Chambre Apostolique au XIVe siècle, Mélanges Paul Fabre: études d'histoire du moyen âge. Paris: A. Picard et fils, 1902.

LEGGE, Alfred Owen. The Growth of the Temporal Power of the Papacy: a historical review. Londres: MacMillan. 1870.

MABILLON, Jean. Musei Italici complectens Antiquos Libros Rituales. Tomo 2. Paris: Edmundi Martin, Johannem Boudot, \& Stephanum Martin, 1689.

MAISTRE, Joseph Maria de. Du Pape. Paris: Carpentier, vol 2, 1841.

MALVES-PONS, C. Conciliation du pouvoir temporel du Pape avec l'indépendance de l'Italie. Paris: E. Dentus, 1860.

M'CLINTOCK, John. The Temporal Power of the Pope (Ed.). New York: Carlton \& Phillips, 1855. MIGNE, Jean Paul. Patrologia Latina Cursus Completus, tomo 98, col. 475, 1841-1855.

MORRIS, Collin. The Papal Monarchy: the western church from 1050 to 1250. Oxford: Clarendon, 2001.

MILEY, John. The History of Papal States: from their origin to the present day. Londres: T. C. Newby, 1850.

MORGHEN, Raffaello. Gregorio VII, Torino: Unione Tipografico - Editrice Torinese, 1945.

MORGHEN, Raffaello. Medioevo christiano, Bari: Editori Laterza, 1962.

MURATORI, Ludovico. Antiquitates Italica Medii Æ $v i$ (Ed.). Vol. 6. Bologna: Forni, 1965.

MURATORI, Ludovico Rerum Italicarum Scriptores (Ed.). Vol. 25. Città di Castello: Casa Editrice S. Lapi, 1914.

OAKLEY, Francis. The Conciliarist Tradition: Constitutionalism in the Catholic Church 13001870. Oxford: Oxford University Press, 2003.

PALAZZI, Thèrese Montecchi. Cencius camerarius et la formation du Liber Censuum de 1192, Mélanges de l'Ecole Française de Rome. Moyen Âge, Temps modernes, vol. 96, n. 1, p. 49-93, 1984. PARTNER, Peter. The lands of St Peter: the papal state in the Middle Ages and the Early Renaissance. Londres: Methuen, 1972.

PENNINGTON, Kenneth. Pope and bishops: the papal monarchy in the twelfth and thirteenth centuries. Philadelphia: University of Pennsylvania Press, 1984.

PACAUT, Marcel. Histoire de la papauté: de l'origine au concile de Trente. Paris: Fayard, 1976. PACAUT, Marcel. La théocratie: L'Église et le pouvoir au Moyen Âge, Paris, Aubier, 1957.

PINA, Jean Rousset de.; FOREVILLE, Raymonde. Du prémier concile de Latran à l'avènement d'Innocent III (1123-1198). Paris: Bloud \& Gay, vol. 1, p. 246, 1953.

RANKE, Leopold von. Die römischen Päpste in den letzen vier Jahrhunderten. Leipzig: Duncker \& Humblot, 1878.

RENARD, Etienne. Polyptyques et inventaires du haut Moyen Âge. Disponível em: www.menestrel.fr/spip.php?rubrique436. Acesso em: 22 fev. 2015.

ROBINSON, Ian Stuart Robinson. The Papacy, 1073-1198: continuity and innovation. Cambridge: Cambridge University Press, 1990.

ROUCHE, Michel. Le Polyptyque de Saint-Pierre-Le-Vif de Sens Pour Saint-Pierre de Mauriac: Grand Domaine ou Grand Revenu?. In: MAGNOU-NORTIER, Elisabeth (Ed.). Aux sources de la gestion publique: enquête lexicographique sur fundus, villa, domus, mansus. Lille: Diffusion Presses Universitaires, 1993.

RUST, Leandro Duarte. Ecos de Pio IX: política e historiografia oitocentistas na criação de um Estado Pontifício para a Idade Média, História Unisinos, v. 16, p. 130-138, 2012. 
SALINIS, Antoine de. Réponse à quelques questions sur le pouvoir temporel du pape. Auch: E. Falières, 1860.

SCHELKENS, Karim; DICK, John A. METTEPENNINGEN, Jürgen, Aggiornamento?: Catholicism from Gregory XVI to Benedict XVI. Leiden: Brill, 2013.

SNIDER-PELLEGRINI, Antonio. Le Pape et son pouvoir temporel. Paris: E. Dentu, 1860.

The Spectator, vol. 23, p. 1000, 1850.

THÉRY, Julien. Le triomphe de la théocratie pontificale, du IIIe concile du Latran au pontificat de Boniface VIII (1179-1303). In: CEVINS, Marie Madeleine de; MATZ, Jean-Michel (Dir.). Structures et dynamiques religieuses dans les sociétés de l'Occident latin (1179-1449). Rennes: Presses Universitaires de Rennes, 2010, p. 17-31.

TOUBERT, Pierre. Europa en su Primer Crecimiento: de Carlomagno al año mil. Valência: Universitat de València, 2006.

ULLMANN, Walter. The Growth of Papal Government in the Middle Ages. London: Methuen, 1955. VAUGHAN, Robert. Contemporary literature, The British Quarterly Review, vol. 52, p. 554, 1870. VERHULST, Adriaan. The Carolingian Economy. Cambridge: Cambridge University Press, 2002. VERÓN, Eliseo. A Produção de Sentido. São Paulo: Cultrix, 1980.

WALEY, Daniel. The Papal State in the Thirteenth Century. Londres: MacMillan, 1961.

WATT, John Anthony. The theory of papal monarchy in the 13th century: the contribution of the canonists. Londres: Burns \& Oatts, 1965.

ZUMTHOR, Paul. A Letra e a Voz: a literatura medieval. São Paulo: Companhia das Letras, 1991. 